\title{
Amiloidose fora de centros especializados: a identificação é possível?
}

\section{Amyloidosis outside specialized centers: is the identification possible?}

Luiz Augusto Fanhani Cracco ${ }^{1}$. Isabela Busto Silva ${ }^{1}$. Edson Marcos Campos Lessa Junior ${ }^{1}$. Gustavo Lenci Marques $^{1}$. Giovanna Vinholi².

1 Hospital Universitário Cajuru, Curitiba, Paraná, Brasil. 2 Pontifícia Universidade Católica do Paraná, Curitiba, Paraná, Brasil.

\section{RESUMO}

Objetivos: relatar a experiência do diagnóstico de amiloidose, uma doença de frequência incomum nos hospitais gerais, através de técnicas simples e acessíveis de coloração histológica. Metodologia: relatamos o caso de um paciente de 57 anos de idade, que foi admitido no departamento de emergência devido a complicações de hipertensão arterial sistêmica com evidências de doença de depósito, submetido à biópsia renal. Resultados: a análise histológica confirmou a presença de depósitos amiloides renais através da coloração cristal de violeta. Conclusões: técnicas histopatológicas simples e acessíveis são métodos viáveis para auxiliar no diagnóstico de amiloidose, uma doença de depósito infrequente em centros não especializados.

Palavras-chave: Amiloidose. Hipertensão. Diagnóstico. Histologia.

\section{ABSTRACT}

Objectives: Report the experience of diagnosis amyloidosis, an unusual disease in general hospitals, using a simple and accessible histological staining techniques. Methodology: We report a case of a patient aged 57 years old, that was admitted in an emergency department due to systemic arterial hypertension with evidences of a deposit disease. Results: The histological analysis confirmed the presence of amyloid deposits through crystal violet staining. Conclusions: Simple and accessible histopathological techniques are viable methods to assist in the diagnosis of amyloidosis, an unusual deposit disease in not specialized centers.

Keywords: Amyloidosis. Hypertension. Diagnosis. Histology.

Autor correspondente: Luiz Augusto Fanhani Cracco, Rua Brigadeiro Franco, 2190, Centro, Curitiba, Paraná, Brasil. CEP: 80250-030. Telefone: +55 41 99912-4798. E-mail: luizaugustocracco@gmail.com

Conflito de interesses: Não há qualquer conflito de interesses por parte de qualquer um dos autores.

Recebido em: 22 Abr 2021; Revisado em: 30 Set 2021; Aceito em: 11 Nov 2021. 


\section{INTRODUÇÃO}

Amiloidose é uma entidade heterogênea, derivada de uma formação proteica anômala. ${ }^{1}$ Caracteristicamente, as proteínas amiloides possuem uma estrutura espacial terciária instável ${ }^{2}$ secundária à dobra proteica inadequada com formação de folhas $\beta$-pregueadas, ao invés de um padrão $\alpha$-helicoidal. ${ }^{3}$ Classicamente, a coloração vermelho do congo associada à luz polarizada é utilizada para detecção das fibrilas amiloides ${ }^{4}$ devido ao típico padrão de birrefringência verde-maçã. ${ }^{5}$ Atualmente, a técnica padrão ouro consiste na microdissecção à laser combinada com espectrometria de massa, ${ }^{5}$ entretanto, é raramente disponível.

O presente trabalho tem por objetivo relatar um caso de amiloidose diagnosticado fora de um centro de referência para tal patologia, evento que se demonstra infrequente, haja vista a pouca ocorrência desta doença nos serviços gerais de saúde. Para tanto, o presente estudo foi adequadamente aprovado pelo Comitê de Ética em Pesquisa da Pontifícia Universidade Católica do Paraná (parecer de aprovação número 4.458.233).

\section{RELATO DE CASO}

Masculino, 57 anos, histórico de hipertensão arterial, utilizando três anti-hipertensivos, com seguimento irregular. Encaminhado ao departamento de emergência de um hospital geral devido epistaxe associada à elevação de pressão arterial
(230 x $120 \mathrm{mmHg}$ ). Exames admissionais demonstraram creatinina sérica $3,58 \mathrm{mg} / \mathrm{dL}$ (Clearance de creatinina estimado por CKD-EPI em $17,8 \mathrm{~mL} / \mathrm{min} / 1.73 \mathrm{~m}^{2}$ ) e ureia $153 \mathrm{mg} / \mathrm{dL}$. Durante a hospitalização persistiu com valores de pressão arterial elevados, e somente com o uso de cinco classes de drogas anti-hipertensivas atingiu valores de pressão arterial sistólica próximos de $160 \mathrm{mmHg}$. Investigação para as causas de hipertensão arterial secundária demonstrou doença parenquimatosa renal. Ecocardiograma transtorácico revelou hipertrofia concêntrica importante de ventrículo esquerdo com fração de ejeção estimada em 46\% (método de Simpson) e massa ventricular esquerda de $249 \mathrm{~g} / \mathrm{m}^{2}$ (VR $115 \mathrm{~g} / \mathrm{m}^{2}$ ), com hipocontratilidade difusa. Relação albumina/ creatinina em amostra de urina isolada $194 \mathrm{mg} / \mathrm{g}$ creatinina. Diante disto, aventada possibilidade de doença de depósito. Realizada biópsia renal que demonstrou expansão mesangial discreta com espessamento da cápsula de Bowman, hialinose arterial circunferencial com arterioloesclerose moderada, túbulos renais com grau discreto de atrofia e espessamento de membranas basais, e focos de depósitos amiloides em paredes vasculares pela coloração cristal de violeta (Figura 1) sendo compatível com hipótese clínica de Amiloidose. Perante os achados e grau de função renal compatível com doença renal crônica avançada, paciente foi referenciado para centro hospitalar terciário especializado.

Figura 1. Amostra histológica renal do paciente em questão: Painel A: Hematoxilina-eosina com presença de espessamento da cápsula de Bowman. Painel B: Ácido periódico com prata metenamina com presença de espessamento de membrana basal. Painéis C, D e H: Cristal violeta com presença de material amiloide. Painel E: Ácido periódico de Schiff (PAS) com diástase demonstrando material eosinofílico, PAS positivo subendotelial nos tufos capilares. Painel F: PAS com hialinose arteriolar. Painel G: Tricrômico de Gomori com alargamento mesangial, discreta hipercelularidade e espessamento da cápsula de Bowman.

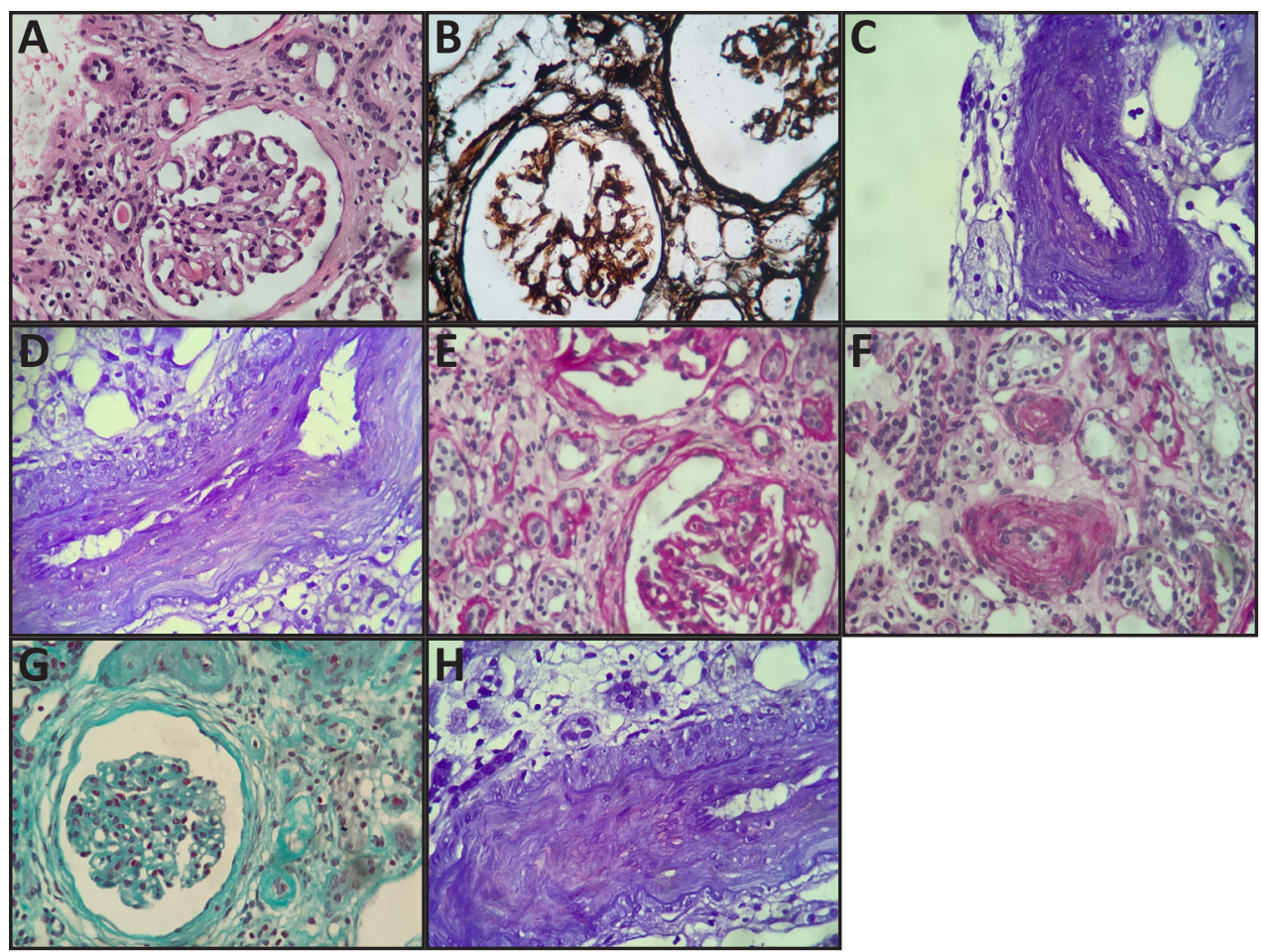




\section{DISCUSSÃO}

Patologia de amplo espectro de apresentação, a amiloidose advém da formação equívoca de alguma proteína, ${ }^{1}$ as quais se agregam no espaço extracelular formando depósitos fibrilares insolúveis e promovendo disfunção orgânica. ${ }^{5}$ Sua prevalência foi estimada em 40,5 casos por milhão (cerca de 12.000 pacientes) nos Estados Unidos da América em 2015. ${ }^{6}$

Descritos por Virchow em 1853, como uma composição de polissacarídeos semelhantes à celulose, ${ }^{7}$ os amiloides vêm sendo analisados de maneira tecnológica, o que fornece informações acuradas desta entidade. Fundamentalmente, a coloração vermelho do congo associada à luz polarizada é utilizada para detecção dos amiloides ${ }^{4}$ devido ao típico padrão de birrefringência verde-maça. ${ }^{5}$ Atualmente, a técnica padrão ouro consiste na microdissecção a laser combinada com espectrometria de massa. ${ }^{5}$

Entretanto, métodos simples são reconhecidos de longa data para a detecção os depósitos amiloides, por exemplo, a coloração cristal de violeta submetida à microscopia de luz comum, utilizada desde os anos $1960 .{ }^{8}$ No presente relato de caso, devido à disponibilidade, esta foi a técnica histopatológica utilizada. A importância deste fato é que, diante de substratos para a suspeita de amiloidose, a investigação inicial pode ser procedida em centros não especializados.

Formas sistêmicas de amiloidose são as mais frequentes, dentre elas, a amiloidose por cadeias leves (AL) e amiloidose reativa secundária a doenças crônicas (AA). ${ }^{1} \mathrm{~A} \quad \mathrm{AL}$ é compreendida dentro das gamopatias monoclonais, onde excesso da produção de cadeias leves de imunoglobulinas leva à agregação e depósito tecidual das mesmas. ${ }^{3,9}$ No caso da AA, inflamação crônica eleva sustentadamente a proteína amiloide A sérica, um elemento de fase aguda, que sofre agregação com consequente formação de depósitos. ${ }^{1,5,9}$

\section{REFERÊNCIAS}

1. Merlini G, Bellotti V. Molecular mechanisms of amyloidosis. N Engl J Med. 2003;349(6):583-596.

2. Fontana M, Ćorović A, Scully P, Moon JC. Myocardial Amyloidosis: The Exemplar Interstitial Disease. JACC Cardiovasc Imaging. 2019;12(11 Pt 2):2345-2356.

3. Priya P Deshpande, Kenar D Jhaveri, The role of the kidney in AL amyloidosis. Nephrology Dialysis Transplantation, 2019; gfz240, https://doi.org/10.1093/ndt/gfz240

4. Dember LM. Amyloidosis-associated kidney disease. J Am Soc Nephrol. 2006;17(12):3458-3471.

5. Bhat D, Asif M, Cooney CM, Schwartz D, Milner SM, Caffrey JA. Amyloidosis associated with skin popping: a case report and review of literature. Int J Dermatol. 2018;57(12):1504-1508.
O coração e os rins são os órgãos mais afetados na $\mathrm{AL},{ }^{9}$ estimando-se nefropatia em até $80 \%$ dos casos, com isto, investigar a doença através da análise do tecido renal torna-se interessante, ${ }^{4}$ especialmente em um cenário de rápida disfunção renal. ${ }^{10}$

A depender da topografia do depósito renal dos amiloides (glomérulos, túbulos ou vasos) a apresentação da doença sofre alteração. ${ }^{3}$ A manifestação renal mais frequente condiz com depósitos glomerulares ${ }^{3-4}$ causando proteinúria assintomática importante ou quadro de síndrome nefrótica franca. ${ }^{3-5} \mathrm{Em}$ uma minoria, o depósito amiloide ocorre nos túbulos renais, promovendo perda de função renal notória com proteinúria discreta. ${ }^{4}$ Já na deposição vascular, a hipertensão é um achado importante, sendo que a mesma é incomum na amiloidose em geral. ${ }^{4}$ Infrequentemente, a apresentação ocorre através de injúria renal aguda com proteinúria não compatível com síndrome nefrótica. ${ }^{3}$

No presente relato, foram encontradas características histopatológicas condizentes com depósitos amiloides em topografia tubular e vascular renal. Sendo que, a clínica apresentada pelo paciente foi de encontro aos dados previamente disponíveis na literatura, com importante perda da função renal, a despeito de uma baixa carga de proteinúria.

As alterações ecocardiográficas que despertaram a suspeita de que não se tratariam apenas de achados secundários a uma hipertensão arterial de longa data com controle inadequado foram, a saber, comprometimento difuso das paredes ventriculares e uma massa ventricular esquerda significativamente elevada. O acometimento cardíaco é descrito em alguns estudos como o maior fator prognóstico, aumentando o risco de morte por insuficiência cardíaca, ${ }^{3} \mathrm{em}$ especial na $\mathrm{AL},{ }^{5}$ sendo que a infiltração ventricular esquerda é iniciada com um padrão de diminuição do relaxamento, progredindo para um padrão de cardiomiopatia restritiva. ${ }^{2}$

6. Quock TP, Yan T, Chang E, Guthrie S, Broder MS. Epidemiology of AL amyloidosis: a real-world study using US claims data. Blood Adv. 2018;2(10):1046-1053.

7. Glenner GG. Amyloid deposits and amyloidosis. The beta-fibrilloses (first of two parts). N Engl J Med. 1980;302(23):1283-1292.

8. Goodman TF, Abele DC, West CS. Electron Microscopy in the Diagnosis of Amyloidosis. Arch Dermatol. 1972;106(3):393-397.

9. Merlini G, Dispenzieri A, Sanchorawala V, Schönland SO, Palladini G, Hawkins PN, et al. Systemic immunoglobulin light chain amyloidosis. Nat Rev Dis Primers. 2018;4(1):38. Published 2018 Oct 25.

10. Sociedade Brasileira de Cardiologia. VII Diretrizes brasileiras de hipertensão. Arq Bras Cardiol. 2016;107(3 supl 3):1-83

\section{Como citar:}

Cracco LA, Silva IB, Lessa EM Junior, Marques GL, Vinholi G. Amiloidose fora de centros especializados: a identificação é possível? Rev Med UFC. 2022;62(1):1-3. 